\title{
Effect of Localized Coating Damage on Stress Corrosion Cracking Resistance of API 5L Grade B Steel
}

\author{
Pejman Malekinejad \\ Department of Materials Science and Engineering, Kerman Graduate University of Technology, Kerman, Iran
}

\section{Email address:}

pejmanmalekinejad2@gmail.com

\section{To cite this article:}

Pejman Malekinejad. Effect of Localized Coating Damage on Stress Corrosion Cracking Resistance of API 5L Grade B Steel. Advances in Materials. Vol. 6, No. 4, 2017, pp. 45-51. doi: 10.11648/j.am.20170604.13

Received: July 28, 2017; Accepted: August 10, 2017; Published: August 28, 2017

\begin{abstract}
In this research slow strain rate testing (SSRT), scanning electron microscopy (SEM), hardness measurement, metallography and optical microscopy were used to investigate the effect of localized coating damage on stress corrosion cracking (SCC) resistance of API 5L Grade B steel. According to the results, by increasing the damaged coating surface area, resistance to SCC increased. This phenomenon had 2 reasons. Firstly, by reduction of damaged surface area of coating, the ratio of anode surface to cathode surface reduced and consequently the corrosion reduced. Other reason was reduction in toughness by reducing the area of damaged surface of coating which resulted in failure at lower stresses.
\end{abstract}

Keywords: API 5L Grade B, SSRT, SEM, SCC

\section{Introduction}

High-strength low-alloy (HSLA) pipeline steels have been used more and more widely all over the world due to their favorable properties. Coincided with the development of the HSLA steels applications, the various aspects of these steels corrosion have been investigated. To date, several studies were conducted to investigate corrosion of pipeline steels in various media such as acidic soil environments and carbonate/bicarbonate solution. Among the various aspects of corrosion, stress corrosion cracking (SCC) has been much interest of researchers. In this relation, there are several studies on the SCC of API X65 and API X70 steels in near-neutral $\mathrm{pH}$ and/or high $\mathrm{pH}$ environments. Some investigators have focused their studies on corrosion of pipeline steels under disbanded coating. Moreover, hydrogen damage of API X70 and corrosion of API X100 have been considered. Although there are a lot of investigates on the corrosion of HSLA pipeline steels, but there are few studies in the case of effect of localized coating damage on stress corrosion cracking resistance. API 5L Grade B steel pipes are considerable candidate due to good combination of strength and toughness, good weldability, low crack sensitivity coefficient and low ductile to brittle transition temperature. These advantages are enhanced due to controlled rolling and controlled cooling techniques used in original coil manufacturing [1]. In most cases, anodic dissolution mechanism of stress corrosion crack growth was the reason for SCC [2].

From years ago, it was believed that three factors are simultaneously necessary for SCC to occur which include corrosive environment, a sensitive metal and tensile stress [3]. As Stryker said in 1985, susceptible mechanisms for SCC are 1- metallurgical mechanisms (planar discontinuities, age hardening and micron disbanding and diffusion), 2- solution mechanisms (film formation on the crack walls according to planar discontinuities, getting rich with respect to the noble element, cracking due to the SCC and migration of Chloride ion), 3- hydrogen mechanisms (hydride formation and hydrogen embrittlement) and 4mechanical mechanisms (tunnel holes and tear and the effect of corrosion products). The susceptibility to SCC under the soil environments is generally proportional to steel strength but inversely proportional to environment $\mathrm{pH}$ value [4]. There are several methods to combat SCC which are pinning, stress relieve heat treatment, control of corrosive environment and reducing the oxidizing elements like oxygen, use of corrosion inhibitors and changing the alloy. In summary the three factors which result in the SCC 
should be prevented $[5,6,7]$. Coatings which are applied on the pipelines are never perfect [8]. Different methods like DCVG (Direct Current Voltage Gradient) and holiday detection are applied to find the defects in coatings. In different forms of electrochemical corrosion according to the corrosion tests of Nyquest, Bode and potentiodynamic polarization test, corrosion rate is proportional to the corrosion current density. But the effect of corrosion current density on SCC as a mechanical corrosion is not yet understood because other factors like metallurgical properties, stress, mechanical properties and engineering shape of the specimen are also important for SCC. The main goal of this study is to investigate the effect of localized coating damage on SCC corrosion resistance of API 5L Grade B steel. I.e. different sizes of defects are applied on the coating and then the SCC behavior of specimen is studied. Also the stress evolution during during SCC is linked to the current density evolution [9].

\section{Materials and Methods}

\subsection{Slow Strain Rate Test}

Slow strain rate test specimens were prepared based on ASTM E08 standard [10]. The dimensions of samples were given in Figure 1 according to that standard. SSRT test was done according to ASTM G 129 standard [11].

The $30 \mathrm{~mm}$ dimension of the below figure was increased in the specimen because of the limitation of tension test device which did not affect the results.

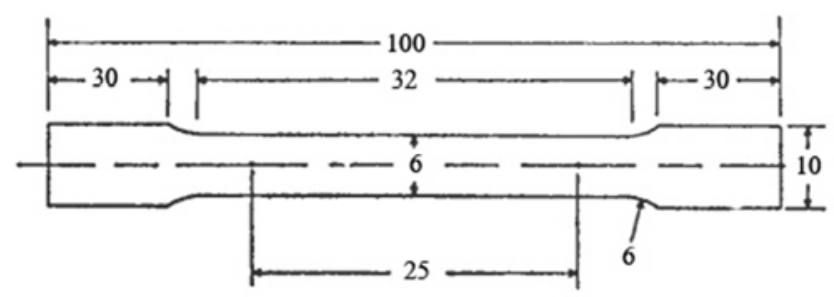

Figure 1. Dimensions in mm of tension test specimen according to ASTM E8 standard.

The material for this specimen was API 5L Grade B steel with chemical composition of Table 1 [12] and thickness of 4.8 millimeter.

Table 1. Chemical composition of API 5L Grade B sheet.

\begin{tabular}{lllllll}
\hline \multirow{2}{*}{$\% \mathrm{Fe}$} & \%Ni+\%Va & \%Ti & \%S & \%P & \%Mn & \%C \\
& Max & Max & Max & Max & Max & Max \\
\hline Remaining & 0.03 & 0.04 & 0.03 & 0.03 & 1.2 & 0.28 \\
\hline
\end{tabular}

After cutting the steel samples by wire cut machine, the samples were polished using emery paper no. 1000 and were degreased using acetone solution. Then the polymer tape coating was wrapped on the samples and finally the defects with widths of $0.1,1,5,10,15$ and 20 millimeters were created on the coating according to Figure 2.

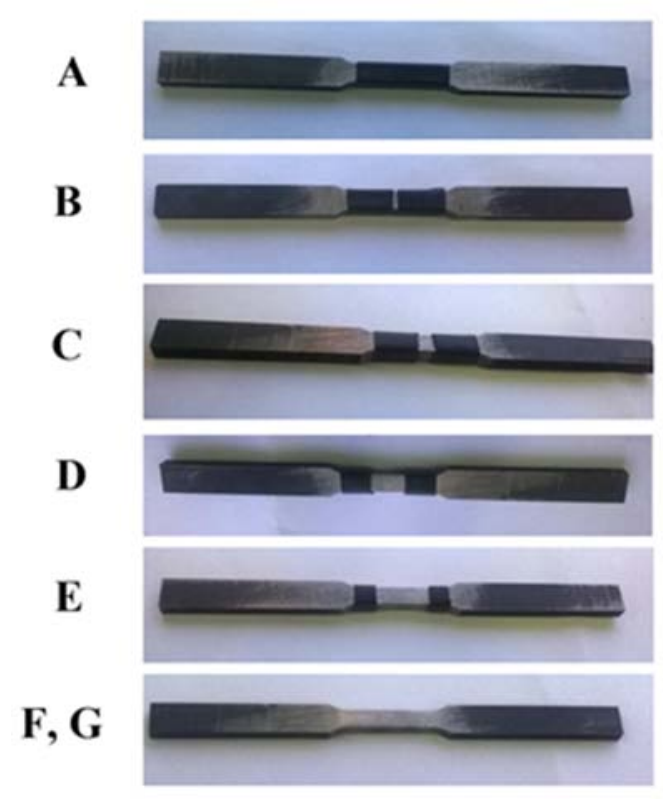

Figure 2. SSRT samples with and without coating defects.

Abbreviations of Table 2 were used all over this study.

Table 2. Abbreviations for samples.

\begin{tabular}{ll}
\hline Abbreviation & Description \\
\hline A & $0.1 \mathrm{~mm}$ width of coating defect, Tested in solution \\
B & $1 \mathrm{~mm}$ width of coating defect, Tested in solution \\
C & $5 \mathrm{~mm}$ width of coating defect, Tested in solution \\
D & $10 \mathrm{~mm}$ width of coating defect, Tested in solution \\
E & $15 \mathrm{~mm}$ width of coating defect, Tested in solution \\
F & Uncoated, Tested in solution \\
G & Uncoated, Tested in air \\
\hline
\end{tabular}

A $0.5 \mathrm{M}$ carbonate-1 M bicarbonate solution was prepared with analytically graded sodium carbonate and bicarbonate salts (Merck, Germany). The slow strain rate tests were conducted in this solution at a strain rate of $0.02 \mathrm{~mm} / \mathrm{min}$. The device for SSRT was INSTRON 5586.

\subsection{Hardness Testing}

Hardness testing was done with portable hardness tester of Equotip 550 Leeb model along 4 points of the specimen according to Figure 3.

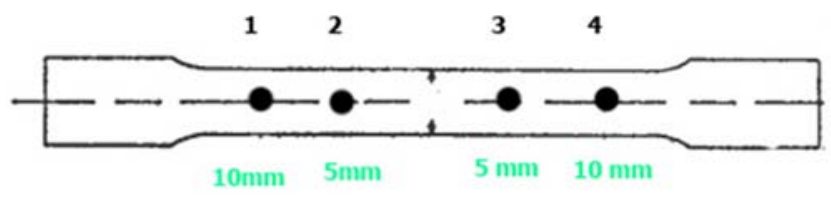

Figure 3. Points across which the hardness testing was done.

\subsection{Metallography}

To perform the metallography, the specimens were first mounted and then were polished to emery papers no. 1200. Then according to ASTM E 407 [13] were etched in the solution of $3 \mathrm{~mL} \mathrm{HNO}_{3}$ and $100 \mathrm{~mL}$ ethanol of $95 \%$. Afterwards, metallography was done using optical microscope. 


\subsection{Scanning Electron Microscopy (SEM)}

Microstructural observations were carried out using the high resolution scanning electron microscope (SEM) MIRA//TESCAN (SE Mode). The fracture surfaces in air and solution were observed to detect the brittle or ductile fracture, cracks and dimples on the cross section of the samples.

\section{Results and Discussion}

As previously said, the aim of this study is to investigate the effect of amount of damage in coating on SCC behavior. To do so, the samples of A, B, C, D, E, F and G were tested by SSRT. Figure 4 shows the result of stress-strain test in SSRT. As it is clear, the $G$ sample had better tensile properties in strength and increase in length. Comparison of the A, B, C, D and E with F curve showed that if the sample was coated, then by decreasing the width of coating damage, mechanical properties were decreased significantly in the solution. Comparison of curves of $F$ and $G$ samples showed that performing the SSRT test in solution will significantly result in decrease in mechanical properties.

Table 3 gives the brief results of tension test with strain rate of $0.02 \mathrm{~mm} / \mathrm{min}$. In this table the following parameters were used to compare the mechanical properties in air and solution:

1. Time of fracture in hour: the basis for calculation was the beginning of loading.

2. Percent of increase in length: the difference in length after fracture and before test.

3. Yield strength in Mpa: upper yield point in Figure 4.

4. Tensile strength in Mpa.

5. Tensile toughness: the area under the stress-strain curve from the beginning of loading until fracture.

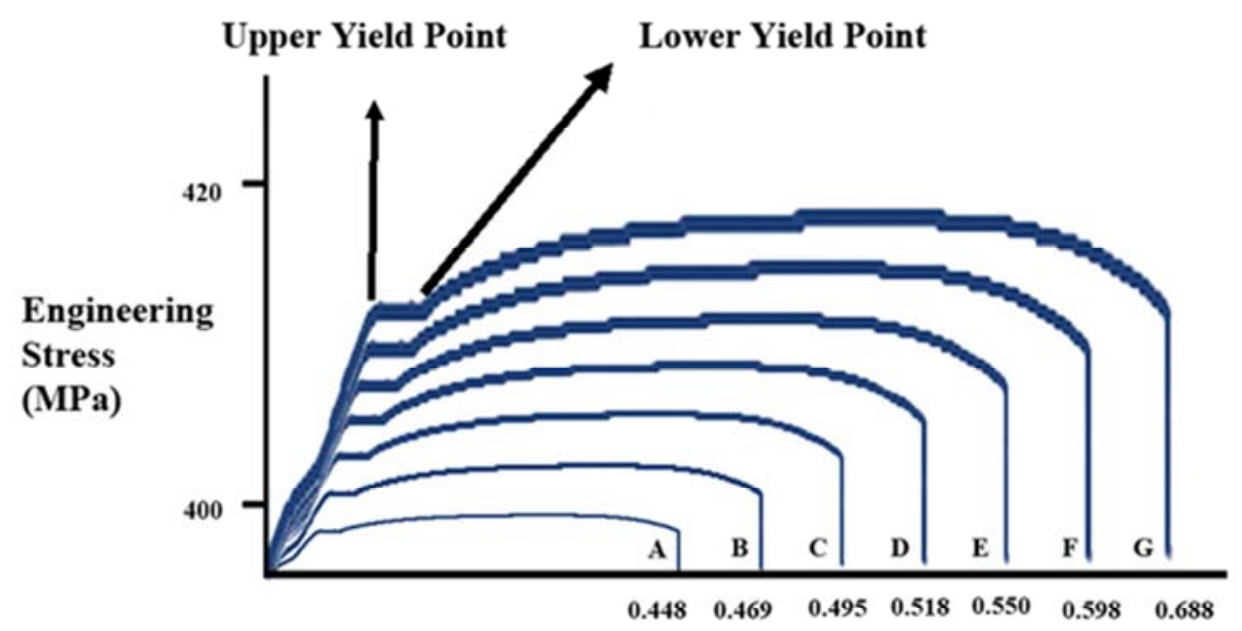

Engineering Strain

Figure 4. Stress strain curves in SSRT test with strain rate of $0.02 \mathrm{~mm} / \mathrm{min}$.

Table 3. Results of tension test in strain rate of $0.02 \mathrm{~mm} / \mathrm{min}$ for the tested samples in air and solution

\begin{tabular}{|c|c|c|c|c|c|c|c|}
\hline & $\begin{array}{l}\text { Time of } \\
\text { Fracture (Hr) }\end{array}$ & $\begin{array}{l}\text { Increase in Length } \\
(\mathrm{mm})\end{array}$ & $\begin{array}{l}\text { Initial Length } \\
(\mathrm{mm})\end{array}$ & $\begin{array}{l}\text { Percent of } \\
\text { Increase in Length }\end{array}$ & $\begin{array}{l}\text { Yield Strength } \\
\text { (MPa) }\end{array}$ & $\begin{array}{l}\text { Tensile Strength } \\
\text { (MPa) }\end{array}$ & $\begin{array}{l}\text { Toughness } \\
\text { (MPa) }\end{array}$ \\
\hline A & 9.765 & 11.2 & 25 & 44.80 & 276.4947 & 404.9317 & 170.9898 \\
\hline B & 10.014 & 11.74 & 25 & 46.96 & 289.6574 & 408.7543 & 175.7657 \\
\hline $\mathrm{C}$ & 10.319 & 12.38 & 25 & 49.52 & 302.3695 & 411.8841 & 180.6543 \\
\hline $\mathrm{D}$ & 10.797 & 12.96 & 25 & 51.84 & 305.1388 & 413.6676 & 186.0098 \\
\hline $\mathrm{E}$ & 11.464 & 13.75 & 25 & 55.00 & 336.125 & 415.3319 & 193.8907 \\
\hline $\mathrm{F}$ & 12.053 & 14.86 & 25 & 59.84 & 349.185 & 417.5432 & 200.6532 \\
\hline $\mathrm{G}$ & 13.773 & 16.12 & 25 & 68.84 & 359.96 & 419.6543 & 214.1335 \\
\hline
\end{tabular}

As it can be seen from the table, all the parameters were decreased from $\mathrm{G}$ to A samples.

The index of susceptibility to SCC $\left(\mathrm{I}_{\mathrm{SCC}}\right)$ was used which was defined as below:

$$
I_{S C C}=\frac{I_{A i r}-I_{S o l}}{I_{A i r}}
$$

In this equation, $\mathrm{I}_{\mathrm{SCC}}$ is susceptibility to SCC. $\mathrm{I}_{\mathrm{Air}}$ the factor measured in air (In this study the parameters for G sample). $I_{\text {sol }}$ is the factor in solution. The results of calculations were given in table 4 . All the indices showed that by decreasing the area of coating damage, susceptibility to SCC increased. The reason for this is that the anodic area is smaller with respect to the cathodic area which resulted in increase in corrosion current and consequently increase in corrosion rate which led to more rapid crack initiation and growth. As it could be seen, the values for toughness were in agreement with the above data which showed that the sample would fail more rapidly in smaller stresses. 
Table 4. Index of susceptibility to SCC.

\begin{tabular}{llllll}
\hline I\% & $\begin{array}{l}\text { Time of } \\
\text { Fracture }\end{array}$ & $\begin{array}{l}\text { Increase } \\
\text { in Length }\end{array}$ & $\begin{array}{l}\text { Yield } \\
\text { Strength }\end{array}$ & $\begin{array}{l}\text { Tensile } \\
\text { Strength }\end{array}$ & Toughness \\
\hline A & 29.100 & 30.521 & 23.187 & 3.508 & 20.148 \\
B & 27.2925 & 27.171 & 19.530 & 2.597 & 17.9177 \\
C & 25.0781 & 23.201 & 16.1017 & 1.86 & 15.6347 \\
D & 21.6075 & 19.603 & 15.3333 & 1.43 & 13.1337 \\
E & 16.7647 & 14.7022 & 6.7356 & 1 & 9.4534 \\
F & 12.4882 & 7.8164 & 3.1118 & 0.5 & 6.2953 \\
\hline
\end{tabular}

For better investigation, hardness testing was also performed. Results of hardness measurement in four points of the samples were given in table 5 in Vickers unit. The hardness of base metal was $110 \mathrm{~V}$. But the hardness of sample in corrosive solution has increased up to $115 \mathrm{~V}$ (Hardness of $\mathrm{E}$ sample near the middle of sample). The reason for this increase in hardness was hydrogen diffusion into the metal. Consequently, the sample was more brittle.

Table 5. Results of Hardness Measurement.

\begin{tabular}{lllll}
\hline & Point 1 & Point 2 & Point 3 & Point 4 \\
\hline A & 110 & 110 & 110 & 110 \\
B & 111 & 111 & 111 & 110 \\
C & 110 & 112 & 112 & 110 \\
D & 110 & 114 & 114 & 110 \\
E & 110 & 114 & 115 & 113 \\
F & 112 & 112 & 112 & 112 \\
G & 110 & 110 & 110 & 110 \\
\hline
\end{tabular}

This caused the movement of dislocations to retard and percent of increase in length decreased. But this mechanism should result in increase in strength whereas the strength decreased. The reason for this behavior was the presence of cracks which had grown in the presence of corrosive environment. Decrease in time of fracture strengthened this theory. When the metallography and SEM photos were studied, no cracks were detected in the structure. This showed that cracks were intergranular. The reason for increase in speed of crack propagation was the metallurgy of the substance, i.e. the extreme brittleness of the matter and decrease in plastic deformation of the crack tip and sharpening of the crack tip which strengthened by anodic dissolution.

In general, the fracture time depended on the following factors:

1. Brittleness of the substance which caused the plastic deformation near the crack tip to decrease and the crack grew more rapidly. Because no more energy will go to plastic deformation.

2. Anodic dissolution: I.e. anodic dissolution occurred at the crack tip and since the metallurgy of material was constant at this study, then plastic deformation around crack would significantly change. This could be seen from SEM images which showed that in all the samples, plastic deformation could be seen. But in general, the plastic deformation has decreased by decrease in area of damage and localizing the corrosion has decreased which was because of anodic dissolution.

Mr. S. Di Liberto and colleagues have said that the reason for SCC was hydrogen diffusion and anodic dissolution for pipeline steel as followed: The phenomenon of transgranular stress corrosion cracking was observed in buried pipelines operating in contact with diluted solutions under disbonded coatings. It was proposed that this kind of cracking is explained by the evolution and permeation of hydrogen at the crack tip, as observed in nuclear pressure vessel steels and other low-alloy steels. The mechanism of transgranular stress corrosion cracking was discussed. The combined effect of hydrogen permeation and anodic dissolution is experimentally investigated by imposing different levels of cathodic protection: from the free corrosion potential $[-750$ $\mathrm{mV}$ (SCE)] to $-1300 \mathrm{mV}$ (SCE). The comparison of the experimental and literature data shows that both anodic dissolution and hydrogen permeation are active and their (synergic) combination gives rise to this particular kind of cracking. Anodic dissolution is active in the crack enclave. At the same time, the cathodic discharge of protons produces hydrogen which enters steel at the crack tip. This phenomenon is intensified for more electronegative potentials. In addition, inside the cracks, the environment becomes more acid than in the bulk and the rates of both anodic and cathodic reactions increase. Hydrogen penetrating into steel increases its brittleness, which depends on the microstructure of the metal and the stress-strain field. This effect was corroborated in this experiments by monitoring the variations of the hardness (brittleness) of steel, observing the formation of internal cracks by optical microscopy, and examining fracture surfaces by scanning electron microscopy [14].

Mr. Li M. C and coworkers have studied the effect of hydrogen on anodic dissolution in SCC of API X70 as followed: Hydrogen-charging enhances the anodic dissolution rate of the steel. The hydrogen-enhanced dissolution increases with increasing charging current density. The hydrogen effect is attributed to the alteration of chemical potential and exchange current density of steel. Hydrogen-charging affects the corrosion process of the steel. In particular, at a high charging current density, a layer of corrosion product forms on the electrode surface to change corrosion potential and interfacial double-charge layer capacitance as well as charge-transfer resistance. The hydrogen effect factor for enhanced anodic dissolution of steel at an anodic potential of $-0.4 \mathrm{~V}$ (SCE) is 1.53 only. Hydrogen-enhanced anodic dissolution of steel by itself may not be the major factor contributing to the high rate of crack growth in pipe steel in near-neutral $\mathrm{pH}$ electrolyte. A further investigation of the synergistic effect of hydrogen and stress on dissolution at the crack-tip is essential to determine the mechanism of near-neutral $\mathrm{pH}$ stress corrosion cracking of pipelines [15].

By increase in damage area, the fracture time increased. Whereas it was prospected that in the samples with greater area of coating damage and greater area in contact with corrosive solution the points of corrosion initiation and the number of cracks attacked by corrosive media was greater. The reason for this behavior was that when the area of damage decreased, the corrosion current increased in that area. 
In order to have better analysis of the nucleation and growth of cracks, the microstructure of base metal was studied. Figure 5 showed the microstructure of base metal by optical microscope.

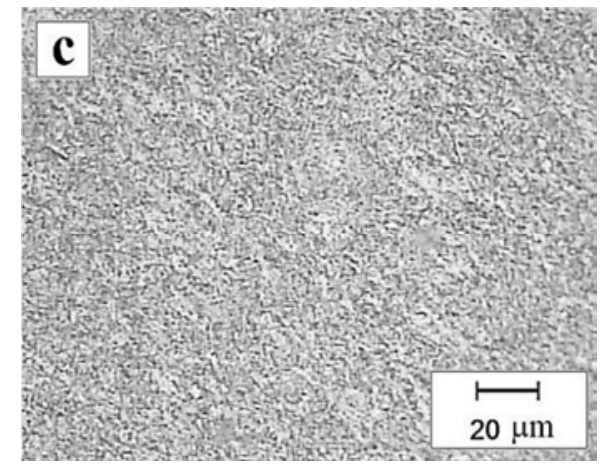

Figure 5. Optical microscope image of the base metal.

As could be seen, the material is very small in grains and the bainite and acicular ferrite in references [16] was not clear. Because of this, high resolution SEM imaging was used.

Figure 6 showed the microstructure of base metal by SEM in two magnifications.
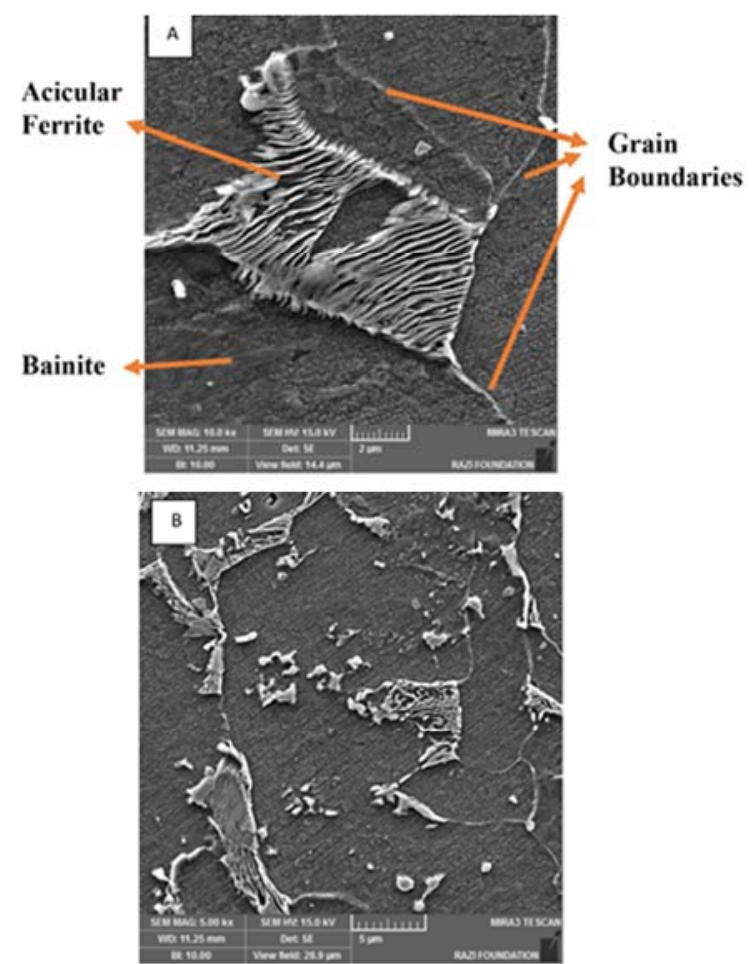

Figure 6. Microstructure of base metal using SEM in two different resolutions.

As it could be seen, there were layer structures beside the grain boundaries. This layered structure is a good location for localized corrosion and nucleation of cracks. In fact, the reason for crack nucleation was anodic dissolution. In the corrosive environment, bainite was as anode for ferrite and was corroded and there was anodic dissolution. Grain boundaries and phases were shown in this figure.

To investigate the fracture behavior in different samples, SEM images were prepared in Figures 7 to 13 at the same magnification.

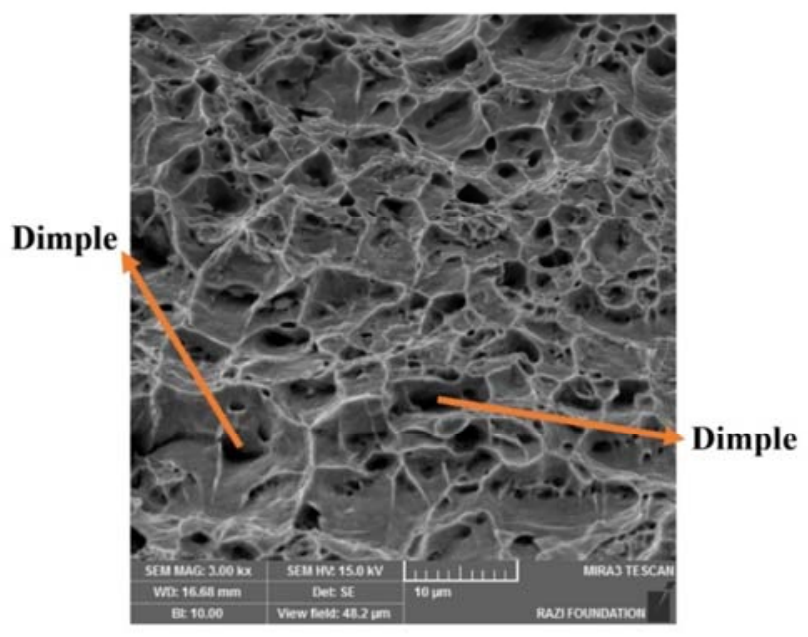

Figure 7. SEM image from fracture surface of $A$ sample.

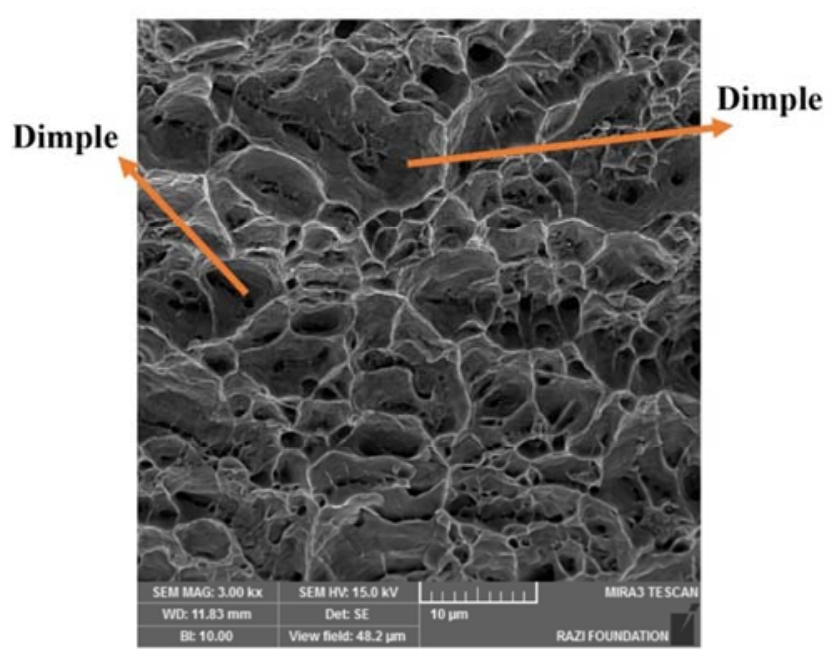

Figure 8. SEM image from fracture surface of $B$ sample.

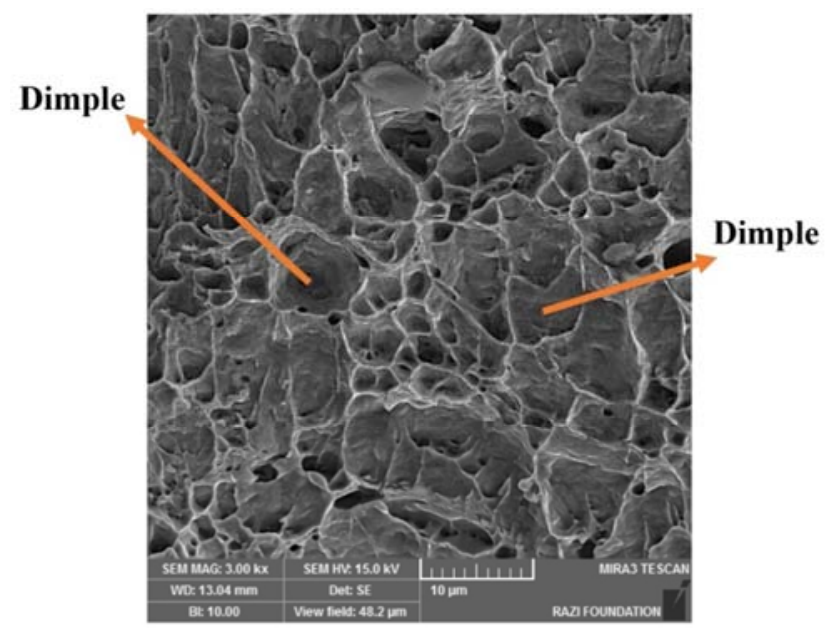

Figure 9. SEM image from fracture surface of $C$ sample. 


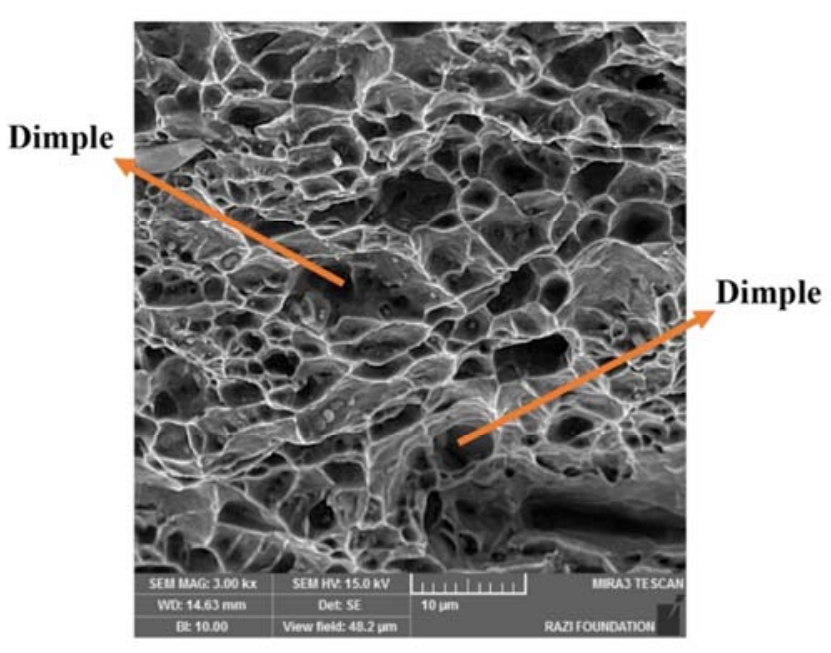

Figure 10. SEM image from fracture surface of D sample.

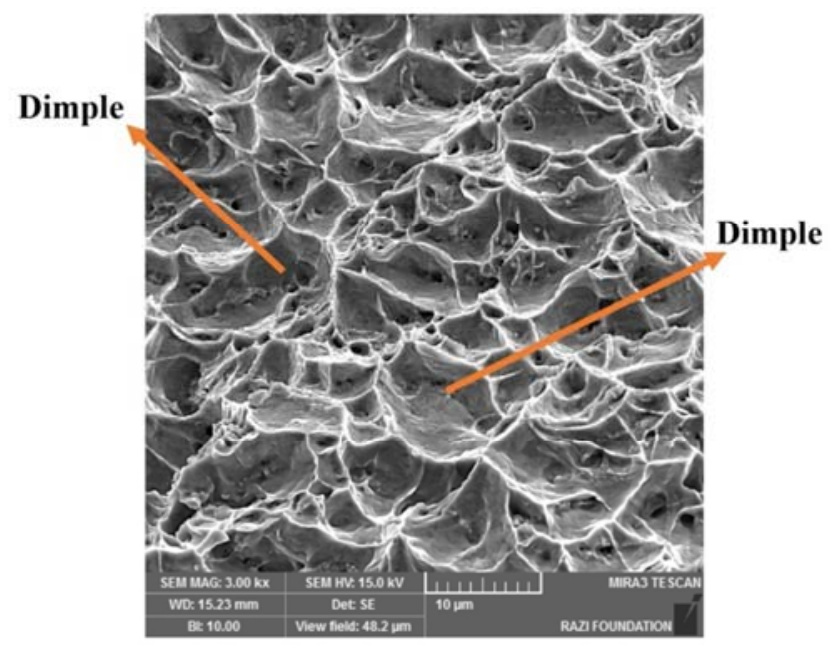

Figure 11. SEM image from fracture surface of E sample.

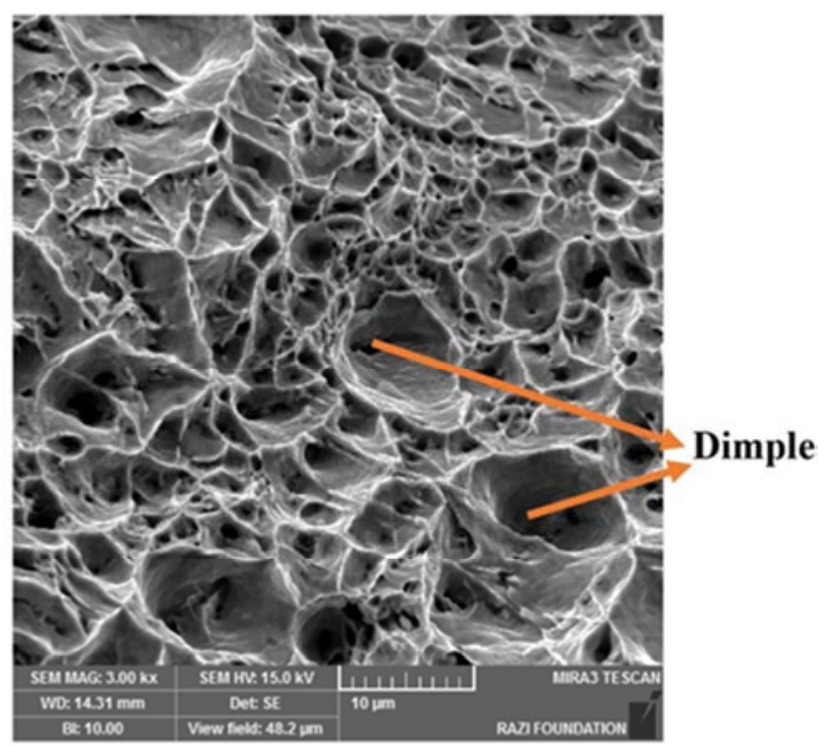

Figure 12. SEM image from fracture surface of $F$ sample.

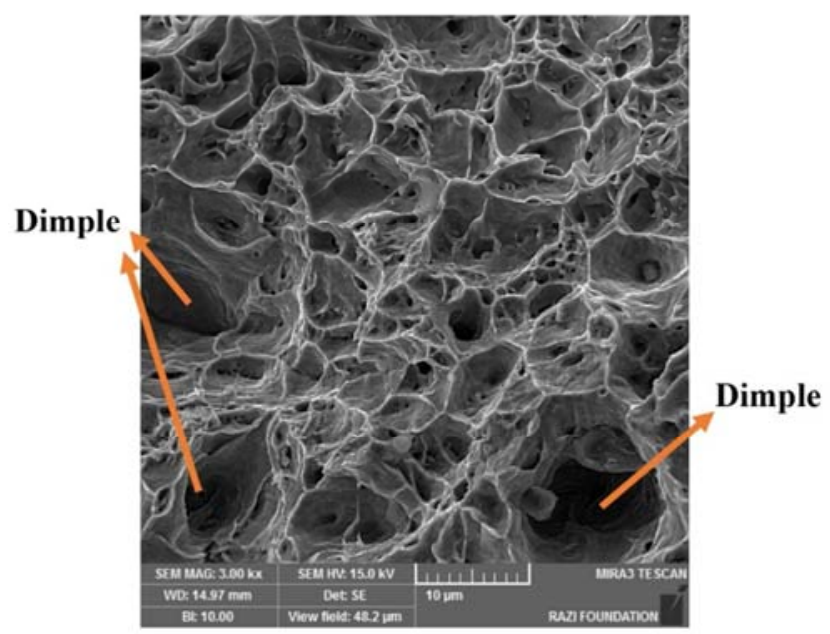

Figure 13. SEM image from fracture surface of $G$ sample.

Comparison of fracture surfaces of different samples in equal magnification showed that in general by decrease of damage area in coating, the amount of dimples which were representative of ductile fracture decreased and the signs of plastic deformation (presence of dimples) has greatly decreased. Also it was clear that in lower magnifications from sample $\mathrm{F}$ to $\mathrm{A}$ the fracture surface became smoother which agreed the brittle fracture. For example, in F sample, in lower magnification damage signs were observed which were not seen in A sample. In fact, the depth of dimples showed brittle or ductile fracture. I.e. by increasing the depth of dimples, the fracture was more ductile.

\section{Conclusion}

It was concluded that susceptibility to SCC increased by decrease in area of damaged coating. Also the corrosion current significantly affected the mechanics of corrosion (crack growth). When the damage to coating was small, since the corrosion current density was constant then the anode surface was smaller than cathode surface and corrosion increased. Furthermore, decrease in toughness of steel was in agreement with decrease in damage of coating. I.e. the sample with smallest damage in coating had smallest toughness and consequently failed sooner and under smaller stresses. The SEM imaging of the fracture surface agreed the above trend. I.e. by increase in damage of coating, susceptibility to SCC decreased. Finally, by decrease in damage of coating, increase in length of the samples has decreased. Since all the samples were from one grade, then this phenomenon has been during the corrosion the reason of which could be hydrogen diffusion into the sample. Hydrogen diffusion caused the locking of discolations and consequently percent of increase in length decreased.

\section{Conflict of Interest Statement}

The author declares that he has no conflict of interest. 


\section{References}

[1] M. Alizadeh, S. Bordbar, The influence of microstructure on the protective properties of the corrosion product layer generated on the welded API X70 steel in chloride solution, Corrosion Science, 70 (2013) 170-179.

[2] Ziqing Zhai, Mychailo B. Toloczko, Matthew J. Olszta, Stephen M. Bruemmer, Stress corrosion crack initiation of alloy 600 in PWR primary water, Corrosion Science, 123 (2017) 76-87.

[3] E. Sadeghi Meresht, T. Shahrabi Farahani, J. Neshati, Failure analysis of stress corrosion cracking occurred in a gas transmission steel pipeline, Engineering Failure Analysis, 18 (2011) 963-970.

[4] Z. Y. Liu, Q. Li, Z. Y. Cui, W. Wu, Z. Li, C. W. Du, X. G. Li, Field experiment of stress corrosion cracking behavior of high strength pipeline steels in typical soil environments, 148 (2017) 131-139.

[5] A. Contreras, S. L. Hernández, R. Orozco-Cruz, R. GalvanMartínez, Mechanical and environmental effects on stress corrosion cracking of low carbon pipeline steel in a soil solution, Materials \& Design, 35 (2012) 281-289.

[6] Z. A. Majid, R. Mohsin, Multiple failures of API 5L X42 natural gas pipeline, Engineering Failure Analysis, 31 (2013) 421-429.

[7] J. G. Erlings, J. G. De Groot, J. Nauta, The effect of slow plastic and elastic straining on sulphide stress cracking and hydrogen embrittlement of 3.5\% Ni steel and API 5L X60 pipeline steel, Corrosion Science, 27 (1983) 1153-1167.

[8] A. W. Peabody, Control of Pipeline Corrosion, NACE International, United States of America, 2001.

[9] Fabienne Delaunois, Alexis Tshimombo, Victor Stanciu, Veronnique Vitray, Monitoring of chloride stress corrosion cracking of austenitic stainless steel: identification of the phases of the corrosion process and use of a modified accelerated test, Corrosion Science, 110 (2016) 273-283.

[10] ASTM E08 standard, Standard test methods for tension testing of metallic materials, ASTM International, 2006.

[11] ASTM G 129, Standard practice for slow strain rate testing to evaluate the susceptibility of metallic materials to environmentally assisted cracking, ASTM International, 2006.

[12] API 5 L Standard, Specification for line pipe, American Petroleum Institute 2004.

[13] ASTM E 407 Standard, Standard practice for microetching metals and alloys, ASTM International, 2006.

[14] S. Di Liberto, G. Gabetta, Stress corrosion cracking by anodic dissolution and hydrogen permeation in pipeline steels, Materials Science, 33 (1997) 411-420.

[15] M. C. Li, Y. F. Chenga, Mechanistic investigation of hydrogen-enhanced anodic dissolution of X-70 pipe steel and its implication on near-neutral $\mathrm{pH}$ SCC of pipelines, Electrochemica Acta, 52 (2007) 8111-8117.

[16] F. F. Eliyan, E. S. Mahdi, A. Alfantazi, Electrochemical evaluation of corrosion behavior of API 5L-X100 pipeline steel in aerated bicarbonate solution, Corrosion Science, 58 (2012) 181-191. 